рья и аквакультуры», Оренбургский государственный университет. Россия.

Килякова Юлия Владимировна, канд. биол. наук, доцент кафедры «Биотехнологии животного сырья и аквакультуры», Оренбургский государственный университет. Россия.

Дускаев Галимжан Калиханович, $\partial-p$ биол. наук, зав. отделом кормления сельскохозяйственных животных и технологии кормов им. С.Г. Леушина,
Федеральный научный иентр биологических систем и агротехнологий РАН. Россия.

Мирошникова Мария Сергеевна, магистр, Оренбургский государственный университет. Россия.

460018, г. Оренбург, просп. Победы, 13.

Тел.: (3532) 37-24-66.

Ключевые слова: растительные экстракты; фитобиотики; кормление рыб; карп; кора дуба.

\title{
EFFECTS OF QUERCUS CORTEX EXTRACT ON THE GROWTH AND DEVELOP-MENT OF CARP
}

Miroshnikova Elena Petrovna, Doctor of Biological Sciences, Professor of the chair "Biotechnology of Foodstuffs from Animals and Aquaculture”, Orenburg State University. Russia.

Arinzhanov Azamat Ersainovich, Candidate of Agricultural Sciences, Associate Profes-sor of the chair "Biotechnology of Foodstuffs from Animals and Aquaculture", Orenburg State University. Russia.

Kilyakova Yuliya Vladimirovna, Candidate of Biological Sciences, Associate Professor of the chair "Biotechnology of Foodstuffs from Animals and Aquaculture", Orenburg State University. Russia.

Duskaev Galimzhan Kalihanovich, Doctor of Biological Sciences, Federal Research Centre of Biological Systems and Agrotechnologies RAS, Federal Agency of Scientific Organizations. Russia.

Miroshnikova Maria Sergeevna, Magistrandt, Orenburg
State University. Russia.

Keywords: plant extracts; phytobiotics; fish feeding; carp; Quercus cortex

Studies have been conducted to determine the effect of feeding Quercus cortex extract in different dosages on the growth and development of carp in comparison with probiotics (Bi-fidobacterium longum) and antibiotics (ciprofloxacin hydrochloride). The studies found an increase in fish growth due to the introduction in the diet of Quercus cortex extracts concen-tration 1 and $2 \mathrm{mg} / \mathrm{kg}$ feed of 7,9\% and $10,7 \%(P<0,05)$, respectively. The inclusion of pro-biotic and antibiotic in the diet showed no significant differences compared to the control group.

\section{ЭКОЛОГИЧЕСКАЯ КОНЦЕПЦИЯ ФУНКЦИОНИРОВАНИЯ ПАРАЗИТАРНОЙ СИСТЕМЫ ПРИ ГИПОДЕРМАТОЗЕ КРУПНОГО РОГАТОГО СКОТА}

\author{
ТОЛОКОННИКОВ Василий Петрович, Ставропольский государственный аграрный университет \\ МАРЧЕНКО Вячеслав Вячеславович, ФГБУ «Ставропольская межобластная ветеринарная \\ лаборатория»
}

ВИКУЛОВА Людмила Сергеевна, ФГБНУ «ВНИИ ветеринарной санитарии, гигиены и экологии» ЧЕПЕЛЕВА Ольга Дмитриевна, Ставропольский государственный аграрный университет СоКОЛОВА Виктория Сергеевна, Ставропольский государственный аграрный университет

Показано, что возбудителями гиподерматоза крупного рогатого скота являются обыкновенный подкожный овод (строка) Нуродеrma bovis De Geer и южный подкожный овод (пищеводник) Нуродегта lineatum De Villers. Приведены данные о повсеместном распространении гиподерматоза в сельскохозяйственных зонах Ставропольского края. Установлено, ито гиподерматоз у крупного рогатого скота чаще регистрируют при пастбищном, чем при стойлово-выгульном содержании. Экстенсивность инвазии у животных, содержащихся в хозяйствах разных форм собственности, составляет 15,4-42,5 \%, интенсивность варьирует в пределах 18,5-29,5 экз./гол. Выявлено, ито активность кожных оводов в биоиенозе в течение суток и весенне-летнего периода регламентируется условиями окружающей среды. Численность популяиий оводов в Ставропольском крае демонстрируется определенным видовым соотношением: Hуродеrma bovis De Geer - 64,7 \%, Hуроderma lineatum De Villers - 33,7 \%. Изучены факторы регулящии численности популящий $\mathrm{H}$. bоvis и H. lineatum.

Введение. Скотоводство как ведущая отрасль животноводства Российской Федерации - основной поставщик молока и производитель мяса, кожевенного сырья, эндокринных препаратов и других ценных продуктов, получаемых при убое крупного рогатого скота [2]. Заразные болезни, к числу которых относится и гиподерматоз крупного рогатого скота, являются сдерживающим фактором успешного развития животноводства. Экономический ущерб при гиподерматозе круп- ного рогатого скота складывается из снижения привесов и удоев. В течение одного года от коровы, пораженной личинками кожного овода, недополучают 80-200 л молока (4,5 \% годового удоя), потеря живой массы у одного инвазированного животного достигает 13-18 кг [5, 13, 15].

В научной литературе отражены результаты исследований биологии, популяционной экологии, фенологии кожных оводов [3, 4, 6, 9], распространения гиподерматоза, патогенеза, эконо- 
мического ущерба, наносимого животноводству, организации мер борьбы с ним [1, 5, 7, 8, 10-15].

Цель настоящего исследования - анализ эпизоотического состояния по гиподерматозу в Ставропольском крае в условиях индустриализации сельскохозяйственного производства, образования новых форм собственности, усложнения инфраструктуры населенных пунктов, сопровождающихся расширением ареала членистоногих, увеличением интенсивности их контактов с человеком и животными, возрастанием эпидемиологической и эпизоотической опасности.

Методика исследований. В процессе исследований учитывали изменения климатических условий последних лет в Ставропольском крае, которые характеризуются увеличением среднемесячной температуры, сокращением продолжительности зимнего и увеличением весеннего, летнего, осеннего периодов. Чтобы установить степень распространения гиподерматоза, проводили экспедиционные выезды в разные сельскохозяйственные зоны края.

Животных подвергали клиническому осмотру при их содержании на пастбищах и ограниченных территориях животноводческих ферм. Учитывали экстенсивность инвазии (соотношение инвазированных животных к общей численности обследованного поголовья) и интенсивность инвазии (подсчет количества паразитирующих личинок на одно животное, экз./гол.). Ежедекадный учет показателей экстенсивности и интенсивности гиподерматозной инвазии проводили в период формирования желваков на кожном покрове животных с марта по июнь включительно.

Результаты исследований. Проведенные нами исследования показали, что гиподерматоз крупного рогатого скота широко распространен в степной зоне Ставропольского края. Своеобразие поведенческих реакций имаго кожных оводов в ответ на постоянно изменяющиеся условия окружающей среды, особенности развития премагинальных фаз паразитов в организме хозяина, афагия имаго, особенности размножения и т. д. демонстрируют пример выраженной экологической пластичности изучаемых видов. Возбудители гиподерматоза при определенных условиях значительно снижают продуктивность своих хозяев и таким образом сдерживают рост численности их популяций. Роль сдерживающего фактора становится более значительной, если учитывать, что насекомые как неотъемлемый компонент синантропного комплекса участвуют в процессах трансмиссивной передачи возбудителей многих болезней заразной этиологии, опасных для здоровья и жизни человека и животных. В этом смысле насекомые имеют большое эпизоотологическое и эпидемиологическое значение.

Следует отметить, что без глубокого изучения межпопуляционных взаимоотношений паразитов (или симбионтов) между собой, паразитоносителями и окружающей средой представления о явлениях паразитизма, патогенности паразитов и защитных реакциях их хозяев будут неполными, следовательно, не объективными [6].

Данные, полученные в ходе наших исследований, свидетельствуют о повсеместном распространении гиподерматоза в Ставропольском крае (табл. 1, 2).

Гиподерматоз у крупного рогатого скота чаще регистрируют при пастбищном, чем при стойлово-выгульном содержании. Экстенсивность инвазии у животных, содержащихся в хозяйствах разных форм собственности, составляет 15,4-47,5 \%, интенсивность варьирует от 18,5 до 29,5 экз./гол. У крупного рогатого скота гиподерматоз наиболее распространен на пастбищах. Это, на наш взгляд, обусловлено более высоким коэффициентом встречаемости паразитов и хозяев в биотопах, чем при содержании на животноводческих фермах, где животные подвергаются регулярным клиническим осмотрам, профилактическим обработкам.

Анализ полученных данных позволил установить закономерность дифференцированного распределения популяции паразитов в популяции хозяина, которая демонстрируется низкой интенсивностью инвазии (2-7 экз./гол.) у 24 \% популяции животных, высокой интенсивностью инвазии (35-40 личинок на 1 гол.) у 1-3\% животных от общей численности обследованного поголовья. У животных основного стада (85 -90 \%) интенсивность инвазии составляла 12-18 экз./гол.

Установили высокий уровень интенсивности инвазии у телят в возрасте до 2 лет (интенсивность

Распространение гиподерматоза крупного рогатого скота в разных сельскохозяйственных зонах Ставропольского края

\begin{tabular}{|c|c|c|c|c|c|}
\hline \multirow{2}{*}{$\begin{array}{c}\text { Сельскохозяйс- } \\
\text { твенные зоны }\end{array}$} & \multirow{2}{*}{$\begin{array}{c}\text { Районы Ставропольского } \\
\text { края }\end{array}$} & \multicolumn{2}{|c|}{$\begin{array}{c}\text { Количество обследованных } \\
\text { животных, гол. }\end{array}$} & \multirow{2}{*}{$\begin{array}{c}\text { Экстен- } \\
\text { сивность } \\
\text { инвазии, } \\
\%\end{array}$} & \multirow{2}{*}{$\begin{array}{c}\text { Интен- } \\
\text { сивность } \\
\text { инвазии, } \\
\text { экз./гол. }\end{array}$} \\
\hline & & всего & $\begin{array}{l}\text { из них инвази- } \\
\text { рованных }\end{array}$ & & \\
\hline I & $\begin{array}{c}\text { Левокумский } \\
\text { Апанасенковский }\end{array}$ & $\begin{array}{l}522 \\
413\end{array}$ & $\begin{array}{l}173 \\
196\end{array}$ & $\begin{array}{l}33,1 \\
47,5\end{array}$ & $\begin{array}{l}25,7 \\
29,5\end{array}$ \\
\hline II & $\begin{array}{l}\text { Благодарненский } \\
\text { Курский }\end{array}$ & $\begin{array}{l}612 \\
416\end{array}$ & $\begin{array}{l}211 \\
177\end{array}$ & $\begin{array}{l}34,4 \\
42,5\end{array}$ & $\begin{array}{l}19,1 \\
21,3\end{array}$ \\
\hline III & $\begin{array}{c}\text { Андроповский } \\
\text { Красногвардейский }\end{array}$ & $\begin{array}{l}366 \\
511\end{array}$ & $\begin{array}{l}120 \\
117\end{array}$ & $\begin{array}{l}32,7 \\
22,8\end{array}$ & $\begin{array}{l}11,3 \\
10,5\end{array}$ \\
\hline IV & $\begin{array}{l}\text { Предгорный } \\
\text { Георгиевский }\end{array}$ & $\begin{array}{l}414 \\
330\end{array}$ & $\begin{array}{l}95 \\
51\end{array}$ & $\begin{array}{l}22,4 \\
15,4\end{array}$ & $\begin{array}{l}17,4 \\
18.5\end{array}$ \\
\hline
\end{tabular}


Показатели экстенсивности и интенсивности гиподерматозной инвазии у крупного рогатого скота при различных условиях содержания

\begin{tabular}{|l|c|c|c|c|}
\hline \multicolumn{1}{|c|}{ Тип содержания } & $\begin{array}{c}\text { Количество обследо- } \\
\text { ванных животных, } \\
\text { гол. }\end{array}$ & $\begin{array}{c}\text { Из них инвазированных, } \\
\text { гол. }\end{array}$ & $\begin{array}{c}\text { Экстенсивность } \\
\text { инвазии, } \\
\%\end{array}$ & $\begin{array}{c}\text { Интенсивность } \\
\text { инвазии, } \\
\text { эк3./гол. }\end{array}$ \\
\hline Пастбищный & 3443 & 1479 & $1,5-49,3$ & $3-51$ \\
\hline Стойлово-выгульный & 3227 & 243 & $1,2-5,75$ & $2-17$ \\
\hline
\end{tabular}

инвазии - 15-7 экз./гол.). У животных 3-5-летнего возраста она составляла 3-11 личинок на одно животное. По нашему мнению, низкий уровень интенсивности гиподерматозной инвазии у животных старших возрастных групп обусловлен тем, что при реинвазии взрослые животные (в обратной связи) демонстрируют более интенсивные реакции местного и гуморального иммунитета.

Видовой состав кожных оводов и их активность в биоценозе. Мы определили, что активность кожных оводов в биоценозе в течение весенне- летнего периода регламентируется особенностями климатических условий зоны содержания животных. Констатировали, что популяции оводов в Ставропольском крае представлены определенным видовым соотношением: Hypoderma bovis De Geer 61,3 \%, Hypoderma lineatum De Villers - 38,7 \%. Паразитический образ характерен только для преимагинальных фаз, паразитизм такого рода называют ларвальным. Имаго - свободноживущие, характеризуются афагией. Кожные оводы развиваются с полным метаморфозом. В течение года дают одну генерацию. Продолжительность жизни имаго варьирует от 3 до 10 сут., при пониженной температуре до 28 сут. Активный лёт оводов в солнечные дни отмечали при температуре $6 . .8^{\circ} \mathrm{C}$, в пасмурные $13 .$. $14{ }^{\circ} \mathrm{C}$. Потенциальная плодовитость самки строки достигает 800, пищеводника - 450 личинок.

Поведенческие реакции оплодотворенных самок оводов обоих видов определяются необходимостью поиска потенциальной жертвы. Оплодотворенных самок чаще регистрировали в местах группового содержания животных. Перед нападением на крупный рогатый скот самки в полете выполняют над животными круговые движения. Этим они вызывают сильное беспокойство у животных, которые перестают пастись, разбегаются в разные стороны, демонстрируют оборонительные реакции. Определив жертву, самки строки размещаются у животных в области тазовых конечностей, паха или крестца и откладывают яйца в гущу волосяного покрова, прикрепляя их к волосам клейкой массой из яйцеклада. Яйца малых размеров малозаметны при внешнем осмотре. Присутствие самок строки обнаруживают по «очагам беспокойства» среди животных. Присутствие самок пищеводника остается для животных незаметным. За одну кладку самка пищеводника прикрепляет к волосам 5-20 яиц и, не вызывая беспокойства животного, улетает.

Факторы регулящии численности популяций H. bovis u H. Lineatum. Динамика численности по- пуляций кожных оводов в реальной обстановке определяется такими факторами, как климатические условия (абиотические факторы), существование и активность других организмов (биотические внутривидовые и межвидовые отношения), антропогенное влияние вследствие хозяйственной деятельности (антропогенные факторы).

В последние 20-30 лет климат Ставропольского края характеризуется сокращением продолжительности зимнего периода и повышением температуры весной, летом, осенью. Зимой температура воздуха не опускается на равнине ниже $-5{ }^{\circ} \mathrm{C}$, летом не достигает абсолютного максимума. Резкие потепления часто превращают зиму в начало весны. Низкие температуры до $10 . . .17^{\circ} \mathrm{C}$ регистрируют чаще в январе - начале февраля.

К факторам, способствующим повышению численности популяций возбудителей гиподерматоза, относят благоприятные климатические условия в зоне их обитания. Большое значение для развития насекомых имеют температура и влажность. В Ставропольском крае оптимальными для развития имаго кожных оводов и их широкого распространения являются условия нежаркого умеренно влажного лета.

Заключение. Гиподерматоз крупного рогатого скота имеет повсеместное распространение в Ставропольском крае. Он чаще регистрируется при пастбищном, чем стойлово-выгульном содержании.

Видовой состав возбудителей гиподерматоза в Ставропольском крае представлен Hypoderma bovis De Geer и Hypoderma lineatum De Villers. Их численность демонстрируется пропорциональным соотношением 64,7: 35,4 \%. Имаго H. bovis, H. lineatum обладают выраженной экологической пластичностью, их сезон продолжается со второйтретьей декад марта до третьей декады декабря.

Особенности трансформации климата в Ставропольском крае диктуют необходимость изучения распространения, биологии, экологии, фенологии, экологической валентности, метаморфоз имаго и преимагинальных фаз кожных оводов в новых условиях.

Уточненные данные биологии кожных оводов создают предпосылки для определения наиболее уязвимых звеньев в популяционном развитии паразитов; корректировки сроков и кратности проведения профилактических мероприятий по борьбе с гиподерматозом, повышения их эффективности и снижения экономического ущерба, наносимого животноводству до хозяйственно не ощутимого уровня. 


\section{СПИСОК ЛИТЕРАТУРЫ}

1. Аверсект-3 при гиподерматозе животных в период лактации / В.А. Дриняев [и др.] // Ветеринария. 2002. - № 5. - С. 30-33.

2. Андрющенко С.А., Васильченко М.Я. Динамика инновационного развития отраслей животноводства // Аграрный научный журнал. - 2018. № 12. - С. $81-84$.

3. Благовещенский Д.И., Павловский Е.Н. К биологии кожного овода (H. bovis De Geer) и меры борьбы с ним // Изд-во прикладной энтомологии. - 1930. Т. 4. - С. 371-399.

4. Благовещенский Д.И., Сердюкова Г.В. К биологии кожного овода и организация борьбы с ним в Закавказье / / Паразитологический сборник; Зоологический институт АН СССР. - М., 1936. - С. 291-311.

5. Болезни животных, вызываемые оводами / А.А. Непоклонов [и др.]. - М., 1980. - 260 с.

6. Бреев К.А. Новые данные о миграции личинок первой стадии H. bovis De Geer в организме хозяина // Паразитологический сборник; Зоологический институт АН СССР. - М., 1967. - Т. 23. - С. 121.

7. Внутрикожное введение авермектинов при паразитарных болезнях молочного стада / В.А. Дриняев [и др.] // Ветеринария. - 2006. - № 1. - С. 33-36.

8. Волков Ф.А., Волкова Е.Ф., Волков К.Ф. Авермектины и милбецины в ветеринарной и медицинской практике. - Новосибирск, 2000. - 43 с.

9. Грунин К.Я. Подкожные оводы. Фауна СССР: двукрылые насекомые. - М.;Л.: АН СССР, 1962. Т. 19. - Вып. 4. - С. 95.

10. Ивермаг при паразитозах крупного рогатого скота / В.П. Хлопицкий [и др.] // Ветеринария. 2006. - № 4. - С. 27-30.

11. Конюхов А.В. Аверсект-2 ВК при паразитарных болезнях крупного рогатого скота // Ветеринария. 2006. - № 6. - С. 6-7.

12. Куничкин Г.И. Подкожные оводы крупного рогатого скота и меры борьбы с ними // Ветеринария. - 1984. - № 11. - С. 34-42.

13. Мамаев Н.X. Краевая эпизоотология, иммунобиологическая реактивность организма животных при гиподерматозе и разработка мер борьбы с ним в Дагестане: автореф. дис. ... д-ра вет. наук. - М., 1971. - 31 с.

14. Непоклонов А.А. Оздоровление стад крупного рогатого // Ветеринария. - 2002. - № 10. - С. 3-6.

15. Ямов В.З. Гиподерматоз крупного рогатого скота // Ветеринария. - 1981. - № 4. - С. 44-47.

Толоконников Василий Петрович, $\partial-p$ вет. наук, проф. кафедры паразитологии, ветсанэкспертизы, анатомии и патанатомии имени профессора С.Н. Никольского, Ставропольский государственный аграрный университет. Россия.

355017, г. Ставрополь, пер. Зоотехнический, 12.

Тел: (8652) 35-22-82; e-mail:W.tol@mail.ru.

Марченко Вячеслав Вячеславович, $\partial-p$ c. $x$. наук, проф., директор, ФГБУ «Ставропольская межобластная ветеринарная лаборатория». Россия.

355035, г. Ставрополь, Старомарьевское шоссе, 34.

Тел: (8652) 28-16-15; e-mail: vmedelika@mail.ru.

Викулова Людмила Сергеевна, аспирант, ФГБНУ «ВНИИ ветеринарной санитарии, гигиень и экологии». Россия.

123022, г. Москва, Звенигородское шоссе, 5.

Тел: (499) 256-35-81; e-mail: sarmat@list.ru.

Чепелева Ольга Дмитриевна, аспирант кафедры паразитологии, ветсанэкспертизы, анатомии u патанатомии имени профессора С.Н. Никольского, Ставропольский государственный аграрный университет. Россия.

Соколова Виктория Сергеевна, аспирант кафедры паразитологии, ветсанэкспертизы, анатомии u патанатомии имени профессора С.Н. Никольского, Ставропольский государственный аграрный университет. Россия.

355017, 2. Ставрополь, пер. Зоотехнический, 12.

Тел: (8652) 35-22-82; e-mail: Sokolovavika1996@ yandex.ru.

Ключевъе слова: гиподерматоз; паразитирующие личинки; крупный рогатый скот; биотоп; популяции; паразитарная система; экологические факторы.

\section{ECOLOGICAL CONCEPT OF PARASITIC SYSTEM FUNCTIONING IN CATTLE HY-PODERMATOSIS}

Tolokonnikov Vasiliy Petrovich, Doctor of Veterinary Sciences, Professor of the chair "Par-asitology, Veterinarian-sanitarian Expertise, Anatomy, and pathological Anatomy named after Professor S.N. Nicholskiy”, Stavropol State Agrarian University. Russia.

Marchenko Vyacheslav Vyacheslavovich, Doctor of Agricultural Sciences, Professor, Stav-ropol Interregional Veterinary Laboratory. Russia.

Vikulova Lyudmila Sergeevna, Post-graduate Student, All-Russian Research Institute of Veterinary Sanitation, Hygiene and Ecology. Russia.

Chepeleva Olga Dmitrievna, Post-graduate Student of the chair "Parasitology, Veterinar-ian-sanitarian Expertise, Anatomy, and pathological Anatomy named after Professor S.N. Nicholskiy", Stavropol State Agrarian University. Russia.

Sokolova Victoria Sergeevna, Post-graduate Student of the chair "Parasitology, Veterinar-ian-sanitarian Expertise, Anatomy, and pathological Anatomy named after Professor S.N. Nicholskiy", Stavropol State Agrarian University. Russia.
Keywords: hypodermatosis; parasitic larvae; cattle; biotope; populations; parasitic system; ecological factors.

It is shown that agents of hypodermatosis of cattle are: ordinary subcutaneous gadfly (string) Hypoderma bovis de Geer and South subcutaneous gadfly (pediatric) Hypoderma lineatumde Villers. The data on the ubiquitous prevalence of hypodermatosis in all agricultural zones of the Stavropol territory are presented. It was established that hypodermatosis in cattle is more often recorded in pasture than stallwalking rearing. The extent of invasion in animals kept in farms of different forms of ownership is 15.4-42.5\%, the intensity of invasion varies within 18.5-29.5 specimens/ head. It is emphasized that the activity of skin gadflies in the biocenosis during the day and spring-summer period is regulated by environmental conditions. Populations gadflies in the Stavropol region demonstrated a certain species ratio of Hypoderma bovis (De Gee - 64.7\%, Hypoderma lineatum DeVillers and $33.7 \%$. The factors of population size regulation of $H$. bovis and $H$. Lineatum were studied. 